They must all feel that they would not have wished him to be other than he was. But if the question must a training he would have been placed in more thorough rapport with his scientific contemporaries; but mathematical training and mathematical capacity were
different things, and it did not follow that Faraday had not a mathematical mind. In Professor Clerk of a very high order, from which, if he had devoted himself to that science. valuable and fertile methods might by him have been discovered.

Sir W. Thomson, in moring a vote of thanks to
Lord Rayleigh for his address, said that the Institution was, during the last part of Faraday's life, and during the whole of his scientitic career, his home. The splendid results of Faraday's labors contributed in no small degree to the scientific glory of the nine-
teenth century, and helped to make it one of the most prolific periods in the world's history. Faraday was He freely gave his discoveries to mankind and left it to others to turn them to practical and profitable account. Faraday pursued science pure and simple, for Wylde showed him the first great machine for trans-
forming mechanical power in to electrical energy, Fara. day remarked, "I gave the discovery to you a baby. day remarked, "I gave the discove

VELOCITIES OF THE IONS.

By Mr. W. C. D. Whetham, B.A.

IN studying electrolysis, the question as to whether is absent presented itself to the author. The ordinary methods of testing for transference, such as by increase
of pressure or by overflow, not being a vailable when of pressure or by overflow, not being a vailable when there was no diaphragm, the author used different is red and the latter blue. By putting the solution into a kind of U-shaped tube, any change in the position of the line of junction of the two liquids could be was the same were also tried, one combination being cupric chloride and common salt, and in this case the line of demarkation traversed about seven inches in
three hours. The results hitherto obtained by this method agreed fairly with those found by Kohl. rausch.

\section{COMPRESSIBILITY OF LIQUIDS}

By Mr. S. Skinner, M.A.

THE apparatus consisted of a large spherical flask with a long narrow neck containing the liquid to be experimented upon, the lower part of which was in with an adjustable reservoir. By raising or lowering or the quantity of liquid adjusted. The flask was in-
closed in a bell jar whose interior was in corrmunicaclosed in a bell jar whose interior was in corrmunica-
tion with a pump and barometer gauge. So sensitive tion with a pump and barometer gauge. So sensitive produced by blowing into the jar caused the liquid to This novement corresponded with a change of volume of about half a millionth. The coefficient of compresthe results were not very different to those obtained by Tait and others. The influence of salts in solution in changing the compressibility had also been tested, electrolytes and non-electrolytes.

AN ELECTROLYTIC PROCESS FOR SILVER AND COPPER ORES

WhEREVER fuel is dear it is certain that the new electroly tic processes for the extraction of metais from their ores will attract considerable attention. In Spain found, most kinds of fuel are far from being cheap, and in such countries the electrolytic processes might well be taken up with advantage. A recent issue of Dingler's Polytechnisches Journal
contains a paper on the Höpfner process of extracting silver and copper from their respective ores by means

Höpfner uses a bath which is separated into compartments by means of diaphragms: generally there are lytically insoluble anodes and in the other copper cathodes.
$\mathbf{A}$ double salt of cuprous chloride and a halogen salt circulates round the anodes, and a similar solution round the cathodes. On the copper spongy copper is
deposited at a rate of $2 \cdot 38$ grammes per ampere hour, when a cupric salt is made use of.

anode some free chlorine was would form, then at the be necessary to have avaln of 1.8 volt. But in this arrangement the liberated chlorine at once unites with the cuprous chloride,
converting it into cupric chloride, equivalent to 1 volt. Hence electrolysis can take place with an electromoti force of 0.8 volt thus-

E M.F. $=1 \cdot 8-1 \cdot 0=0.8$.

Theoretically, the electrolysis commences with the consumption of $0 * 13$ volt. This can be deduced by cupric chlorides.
As the liquid flows past the cathode it gradually parts with its copper, and is available for use again ; but the copper is, of course, now present as cupric
chloride instead of cuprous chloride, and the latter is made to leave the bath in a continuous stream. This solution is employed in an industrial way for extracting
the metal from powdered copper and silver ores, special "leaching" vessels being employed. following reaction takes place, vi

$\mathrm{Cu}_{\mathrm{Cl}}+\mathrm{Cu} \mathrm{S}=\mathrm{S}+\mathrm{Cu}_{2} \mathrm{Cl}_{2}$

The solution of the bat it is twice as strong now as before, and so it is
ecessary to dilute it in order to bring it back to its ixing it with the waste liquors that come away from The cathodes. The process, as will readily be seen, may be worked This process would work admirably were it not for
ver the influence of certain natural drawbacks. Sometimes there is present in the ores small quantities-perhaps
only traces-of such substances a.s iron, arsenic, bismuth, antimony, etc., and these will pass into solution
moth stead of the copper. Thepresence of iron is especialobjectionable, since it very sensibly retards the Teing treated. to deposit along with the copper. Fortunately, howver, it is by no means difficult to eliminate them, for
con easily separated of

In working with silver and copper ores, the former metal, if it be present, is first deposited, and the result ing copper is obtained in a chemically pure condition. ine of Hopfner's process are the following: phate of copper when the same intensity of current is 2. Solutions free from iron can be made use of be-
employed. cause the alkaline and alkaline earth chlorides possess respect also this process is superior to the copper sul3. The most impure ores may be used, yet pure
opper may be obtained, and from silver-bearing ores the silver may be deposited at the same time.

4. Forty-four kilogram mes of copper may be obtained 5. When reckoning

chanical and the the electro-dynamic power at three quarters, of the total work necessary to do the operation, then with an xpenditure of $30 \mathrm{kilogrammes}$ of coal, 33 hilogrammes copper mav be obtained.

An examination of the figures just quoted will show
that the results obtained by the Hoppner process of that the results obtained by the Horpfner process of
electrolyzing ores are higher than any which have electrolyzing ores are higher than any which have
hitherto been reached-so high, indeed, that the Revie

INTERNATIONAL BICYCLE RACE FROM BORDEAUX TO PARIS.

ON the morrow of the international race from Borand the daily press have furnished the public with the completest details, it is not without interest to reconding.

Retracing in broad lines the various phases of the contest in which our English competitors so splendidly ant future, this momentary defeat of our follow rymen may give way to brilliant victories.

In the first place, let us in a few lines recapitulate selves more particularly to the race, in devoting ourto draw a lesson. The start from Bordeaux took place on May 23, at 5 o'clock in the morning. Our large graph, shows us the grouping of the racerso Twentyseven cyclists, placed in five rows, signed their road book. The following is an exact list, to which we add seven minutes after the others: J. Renault (Paris), H.
Gillot (Paris), Jiel-Lavat (Bordeaux), P. G. Mills (EngGillot (Paris), Jiel-Lavat (Bordeaux), P. G. Mills (Eng-
land), P. Rousset (Bordeaux), H. Tart (Orleans) Mr. England), P. C. Twentyman (England), Mr. Guillet Blain), Mr. Exben (Bordeaux), A. Duphon (Bordeaux),
G. Juzan (Bordeaux), H. Ulrich (Sevres), L Gebleux, Sevres), Mr. Bates (England), A. Desse (Royan), H.
Jules (Paris), Mr. Coullibouf (Vendome), Mr. Corre ules (Paris), Mr. Coullibøuf (Vendome), Mr. Corre
Plestin-les-Greves), E. Pierre (Nancy), Mr. Bailly (Saint
Amand), L. Masi (Switzerland), Mr. Issot (Royan), Mr. Huzelstein (Pamiers). J. Jouve (Bordeaux), Mr. Ey quem Bordeaux). All of these racers were bicyclists, save
ne, Mr. Rousset, of Bordeaux, their dean, aged fifty-
These adventitious impurities must not be allowed

1. By electrolyzing cuprous chloride solution, the which would be thrown down from a solution of suly this method in twenty-four hours with an expendiThe five Englishmen took the lead from the start, so

Mr. Masi, of Switzerland, got a fall through the fau/t a dog, and had his left arm badly bruised. Beyond rench cyclist Jiel-Laval who in endeavoring to steer clear or him, collided with Mr. Mills, whom he over bicycle bent, but was still able, on his damaged machine, to make 12 miles, at the end of which a trainer furnished him with one that was in a good state. I have noted these two accidents, which were due to
dogs, and which, seeing the speed of the cyclists, might dogs, and which, seeing the speed of the cyclists, might
have turned to tragedy, in order to point out the dif-
ference that exists in this respect between English and rench dogs. In our country, horses and dogs are horses take fright at the sight of the rolling machine.

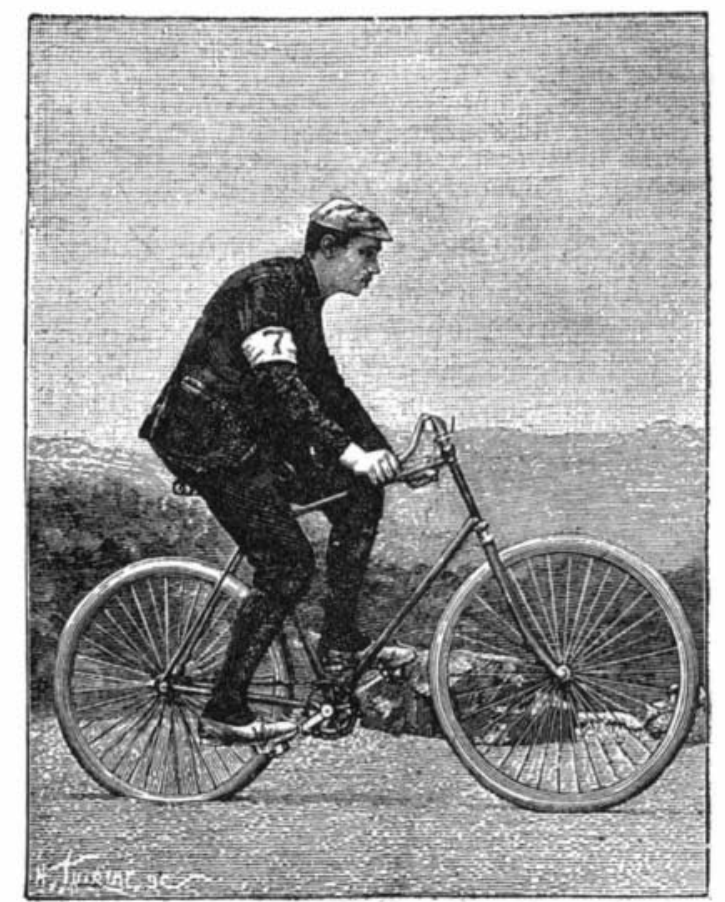

FIG, 1-MR, MILLS, THE VICTOR IN THE BORDEAUX-PARIS BICYCLE RACE

The duty of the cyclistin such a case is to dismount and wait until the animal has passed on or been quieted.
As for dogs, a large number of them rush in front of the machine and bark at it, just as they do in the difference in speed between the two kinds of vehicle. The bicycle passes over their body and is upset and the rider gets a fall that is often very serious, while the
dog gets off very lightly, especially if he is of a strong build. Contrary to what occurs with carriages, it is the one run over that receives the least harm; ;
for the rider, he may be killed instanter. So the French $\mathrm{dog}$ is the terror of cyclists, who are further fortunate when it is not the owner of the animal that excites the "atter against them, as this has been too often done "Le Vhien, viola l'ennemi," exclaims our confrere of r. Duncan, a cyclist correspondent, to an Englisl complaint would be at once lodged against a dog hit jumped upon a cyclist, and its owner would be this respect, does not receive all the protect which he is entitled, and complaints, save in cases of very serious accidents, are rarely listened to. So the horsewhip near his hand, the protection offered by wich is very of ten but illusory.

machines employed were, for the most part, of the ty pe intermediate between the light racing machin road machine, which is lighter, but not so
trong. It was found with patriotic satisfaction that

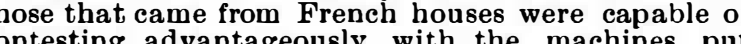
contesting advantageously with the machines put orth by English manufactories. We must state that the

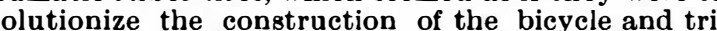
cycle, have not performed what they apparently promwheels, while at the same time pres

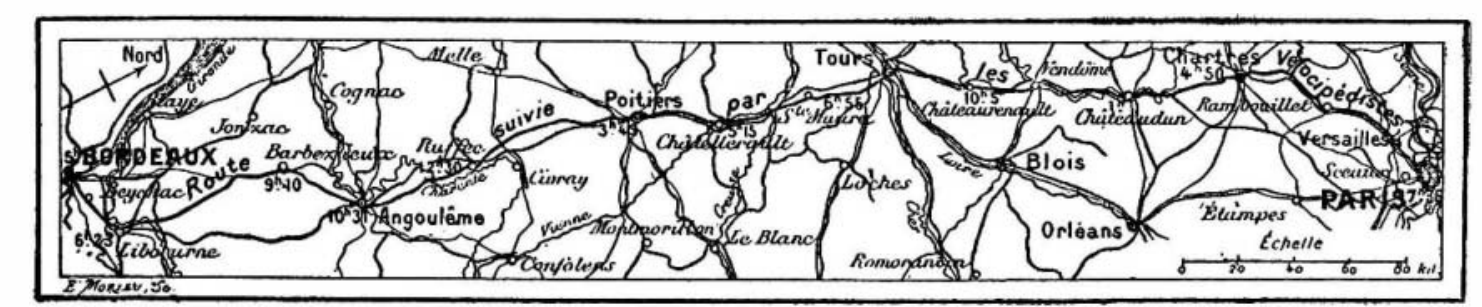

Fig. 2.-MAP OF THE ROUTE, GIVING MILLS' hOURS OF PASSING THE DIFFerent LOCALITIES.

as to leave their competitors immediately behind them. upon a well leveled track, they are difficult to use The hours of passage were verified at various points of
the route, the cyclists having to dismount in order to
is necessarv to improve them greatly in order to render the route, the cyclists having to dismount in order to is necessary to improve them greatly in order to render
sign a register prepared for the purpose. They took
them practical. In fact, most of them split on the way advantage of this to refresh themselves in haste, and and put the machines with which they were provide station. may very clearly see the principal points of the lateral sliding, either through striæa or otherwise. The itinerary, with the hours of passage of Mr. Mills, the best of our cyclists, Mr. Jeil-Laval, fell, in fact, at the
first to reach Paris. The details of the hours of pas- start, in consequence of a sliding upon viscous earth. first to reach Paris. The details of the hours of pas- start, in consequence of a sliding upon viscous earth.
sage of the various competitors would lead us too far; As well known, the race was made in very bad weather sage of the various competitors would lead us too far;
it is the incidents of the route that we wish to note here, in accompanying them with some reflections that As well known, the race was made in very bad weather
and over roads softened by rain. and over roads softened by rain.
Let us now return to the race and follow the group

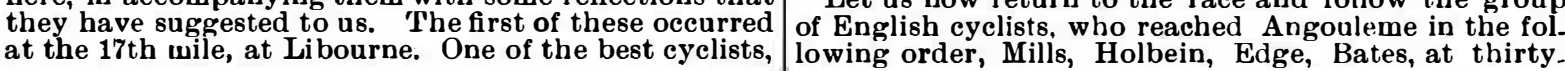

